\title{
The Basicity of Alkali Metal Methoxides in Methanol. The Effects of Ion Association on Methoxide Additions to Activated Anisoles
}

\author{
Paula C. M. F. Castilho, Michael R. Crampton * and Jack Yarwood \\ Department of Chemistry, The University, Durham DH1 $3 L E$, UK
}

The formation of adducts with $1: 2$ and $1: 3$ stoichiometry by methoxide addition to nitro-activated anisoles has been examined spectrophotometrically. For these equilibria the 'basicity' of sodium methoxide solutions in methanol is appreciably greater than that of corresponding potassium methoxide solutions. This is in contrast with other measures of basicity and is attributed to the association of the multi-charged adducts with cations which is stronger with sodium than with potassium ions.

Solutions of alkali metal methoxides in methanol have been widely used as strongly basic media for the study of rates and equilibria of reactions. ${ }^{1-3}$ Attempts have been made to quantify the basicity of these media using acidity functions. ${ }^{1-5}$ When ionisation involves proton loss, eqn. (1), the $H_{\mathrm{M}}$ function, defined in eqn. (2), is appropriate. With aromatic amines as indicators

$$
\begin{gathered}
\mathrm{SH}+\mathrm{MeO}^{-} \rightleftharpoons \mathrm{S}^{-}+n \mathrm{MeOH} \\
H_{\mathrm{M}}=\mathrm{p} K_{\mathrm{SH}}+\log _{10} \frac{\left[\mathrm{S}^{-}\right]}{[\mathrm{SH}]}
\end{gathered}
$$

values of $H_{\mathrm{M}}$ fall, at a given base concentration, in the order $\mathrm{KOMe}>\mathrm{NaOMe}>\mathrm{LiOMe}$. This order has been attributed to ion-association in the metal alkoxides which results in a reduction in their activities, the effect being greatest for lithium methoxide and smallest for potassium methoxide. ${ }^{4,6}$ Values of $H_{\mathrm{M}}$ may also be affected by differences in the relative solvation of reactants and products [i.e. the value of $n$ in eqn. (1)]. Thus scales obtained using the ionisation of indole derivatives, ${ }^{5}$ where the anions are expected to be well solvated leading to low values of $n$, increase less steeply with base concentration than those obtained with the aromatic amines. Nevertheless the basicity order $\mathrm{KOMe}>\mathrm{NaOMe}>\mathrm{LiOMe}$ is preserved.

Recently the 'excess basicity' approach has been applied to solutions in methanol of metal methoxides. ${ }^{7}$ Again the two important factors were thought to be ion-association of the methoxides, so that the basicity decreased in the order $\mathrm{KOMe}>\mathrm{NaOMe}>\mathrm{LiOMe}$, and differences in solvation, reflected in variations in the value of the parameter $m^{*}$ which relates activity coefficient ratios.

For parent molecules which react by the covalent addition of methoxide ions to give $\sigma$-adducts eqn. (3), the basicity may be

$$
\begin{aligned}
& \mathrm{P}+\mathrm{OMe}^{-\stackrel{K}{\rightleftharpoons}} \mathrm{P} \cdot \mathrm{OMe}^{-}+m \mathrm{MeOH} \\
& J_{\mathrm{M}}=\mathrm{p} K+\mathrm{p} K_{\mathrm{MeOH}}+\log _{10} \frac{\left[\mathrm{P} \cdot \mathrm{OMe}^{-}\right]}{[\mathrm{P}]}
\end{aligned}
$$

represented by the $J_{M}$ function, eqn. (4). ${ }^{1-4,8}$ It has been shown that a third factor, in addition to those already stated, is important here and this is ion-association of the adducts, $\mathrm{P}^{\circ} \mathrm{OMe}^{-}$, with cations. In particular it is known that 1,1dimethoxy adducts of the type 1 associate strongly with metal ions. ${ }^{9-12}$ Further, since the ion-pair association constants vary with the nature of the substrate, no single $J_{M}$ function can adequately describe the behaviour of all compounds. ${ }^{9}$ At high methoxide concentrations addition at two or three ring

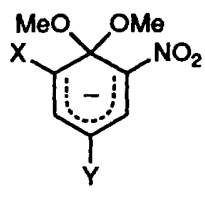

1

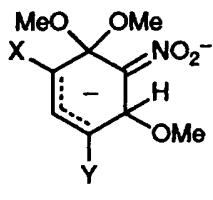

2

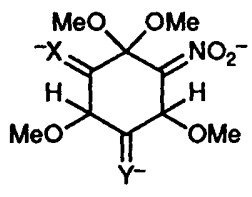

3 positions may lead, respectively, to the formation of adducts 2 with $1: 2$ stoichiometry, and 3 , with $1: 3$ stoichiometry. ${ }^{4,8,13}$ Here we examine the dependence of these higher equilibria on the base concentration in sodium methoxide and in potassium methoxide solutions. Our results show that for these interactions the 'basicity' of sodium methoxide may be considerably greater than that of potassium methoxide at the same concentration. We attribute this to specific interactions with cations of the higher adducts which are stronger with sodium than with potassium ions.

\section{Experimental}

The following substrates were recrystallised samples available from previous work: 2,4,6-trinitroanisole, ${ }^{9}$ m.p. $68^{\circ} \mathrm{C}$ (lit. ${ }^{14}$ $68^{\circ} \mathrm{C}$ ); 4-cyano-2,6-dinitroanisole,,$^{11}$ m.p. $113^{\circ} \mathrm{C}$ (lit., ${ }^{15} 114^{\circ} \mathrm{C}$ ); 2-cyano-4,6-dinitroanisole, ${ }^{11}$ m.p. $73^{\circ} \mathrm{C}$ (lit., ${ }^{16} 72^{\circ} \mathrm{C}$ ); 1 (2-hydroxyethoxy)-2,4,6-trinitrobenzene, ${ }^{17}$ m.p. $60^{\circ} \mathrm{C}$ (lit., ${ }^{17}$ $61{ }^{\circ} \mathrm{C}$ ). Sodium and potassium methoxide solutions were prepared by dissolving clean samples of the respective metals in Analar methanol under nitrogen. Concentrations were determined by titration with standard acid. UV-VIS measurements were performed at $25^{\circ} \mathrm{C}$ with a Perkin-Elmer Lambda 3 instrument; test solutions were referenced to base solutions of the same concentration. Where reaction solutions were unstable readings were taken for sufficient time to allow accurate extrapolation to the required zero time values.

\section{Results}

For all the substrates studied conversion into mono-anionic $\sigma$ adducts 1 was $>99 \%$ complete in solutions containing $0.5 \mathrm{~mol}$ $\mathrm{dm}^{-3}$ base. At higher base concentrations reversible changes in UV-VIS spectra were observed which are compatible with the formation of adducts 2 and 3 with 1:2 and 1:3 stoichiometries, respectively. ${ }^{4,8,13}$ The measured absorbances were used to calculate indicator ratios as detailed below.

2,4,6-Trinitroanisole.-Data obtained with sodium methoxide have been analysed previously by Rochester. ${ }^{8}$ We find that the adduct $1\left(\mathrm{X}=\mathrm{Y}=\mathrm{NO}_{2}\right)$ formed with potassium methoxide has $\lambda_{\max } 410 \mathrm{~nm}\left(\varepsilon 2.47 \times 10^{4} \mathrm{dm}^{3} \mathrm{~mol}^{-1} \mathrm{~cm}^{-1}\right)$ and $484 \mathrm{~nm}(\varepsilon$ 
Table 1 Absorbance data for solutions of 2,4,6-trinitroanisole ${ }^{a}$ in methanolic potassium methoxide

\begin{tabular}{|c|c|c|c|c|c|c|}
\hline \multirow[b]{2}{*}[\mathrm{KOMe}]{$/ \mathrm{mol} \mathrm{dm}^{-3}$} & \multicolumn{3}{|c|}{ Absorbances/nm } & \multicolumn{3}{|c|}{$\begin{array}{l}\text { Relative } \\
\text { concentrations }\end{array}$} \\
\hline & 410 & 436 & 484 & 1 & 2 & 3 \\
\hline 0.80 & 0.750 & 0.390 & 0.505 & 1.0 & 0 & 0 \\
\hline 1.17 & 0.750 & 0.380 & 0.502 & 1.0 & 0 & 0 \\
\hline 1.64 & 0.750 & 0.390 & 0.514 & 1.0 & 0 & 0 \\
\hline 1.87 & 0.747 & 0.390 & 0.522 & 0.99 & 0.01 & 0 \\
\hline 2.34 & 0.730 & 0.385 & 0.555 & 0.96 & 0.04 & 0 \\
\hline 2.57 & 0.708 & 0.383 & 0.576 & 0.92 & 0.08 & 0 \\
\hline 2.69 & 0.691 & 0.380 & 0.585 & 0.88 & 0.12 & 0 \\
\hline 3.04 & 0.625 & 0.375 & 0.652 & 0.75 & 0.25 & 0 \\
\hline 3.39 & 0.525 & 0.380 & 0.738 & 0.56 & 0.44 & 0 \\
\hline 3.54 & 0.427 & 0.352 & 0.802 & 0.40 & 0.53 & 0.07 \\
\hline 3.74 & 0.360 & 0.340 & 0.840 & 0.28 & 0.61 & 0.11 \\
\hline 3.94 & 0.270 & 0.307 & 0.865 & 0.15 & 0.66 & 0.19 \\
\hline 4.14 & 0.207 & 0.288 & 0.890 & 0.05 & 0.71 & 0.24 \\
\hline
\end{tabular}

${ }^{a}$ Concentration is $3.038 \times 10^{-5} \mathrm{~mol} \mathrm{dm}^{-3}$.

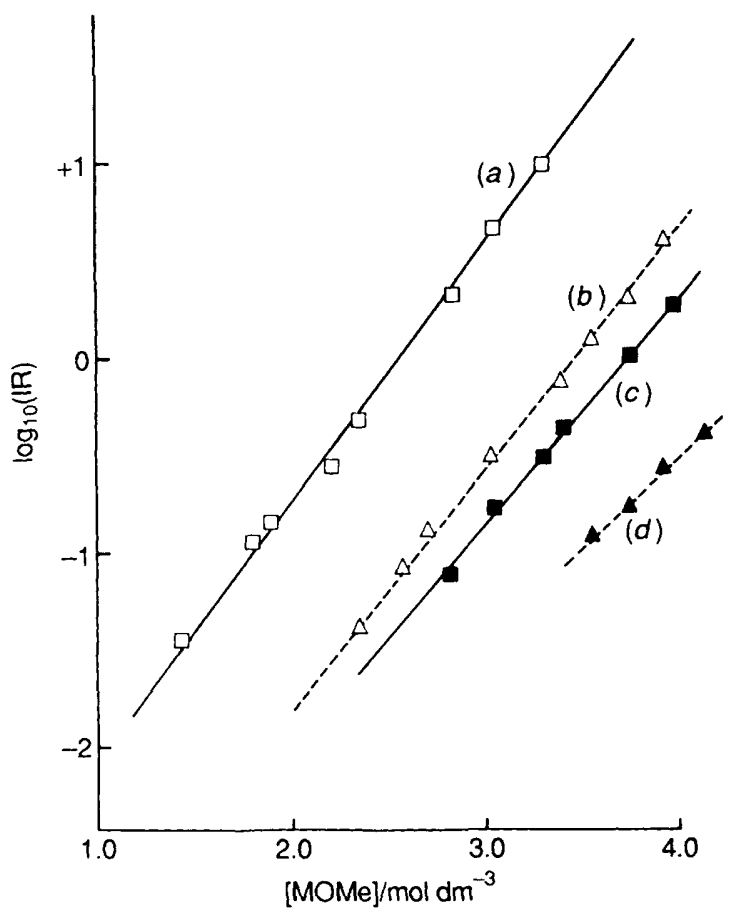

Fig. 1 Adduct formation from 2,4,6-trinitroanisole; $\log _{10}\{[2 /[1]\}$ vs. [MOMe] for sodium methoxide $(a)$ and potassium methoxide $(b)$. $\log _{10}\{[3] /[2]\}$ vs. MOMe for sodium methoxide (c) and potassium methoxide $(d)$. IR = indicator ratio.

$1.65 \times 10^{4}$ ). In the range $1.8 \mathrm{~mol} \mathrm{dm}^{-3}<[\mathrm{KOMe}]<3.5 \mathrm{~mol}$ $\mathrm{dm}^{-3}$ the absorbance at $410 \mathrm{~nm}$ decreases while that at higher wavelength increases, consistent with the formation of the $1: 2$ adduct, 2. However, in this range an isosbestic point is observed at $436 \mathrm{~nm}$. At even higher base concentrations the absorbances at $436 \mathrm{~nm}$ decrease providing evidence for the formation of the $1: 3$ adduct 3 , which is transparent in the visible region. ${ }^{4,8}$ The results in Table 1 were analysed to give the relative concentrations of adducts using eqns. (5)-(7). Eqn. (5) makes

$$
\begin{gathered}
{[1]+[2]=\frac{\text { Absorbance }(436 \mathrm{~nm})}{0.38}} \\
{[3]=1-[1]+[2]} \\
\text { Absorbance }(410 \mathrm{~nm})=0.75[1]+0.24[2]
\end{gathered}
$$

Table 2 Absorbances for solutions of 4-cyano-2,6-dinitroanisole ${ }^{a}$ in sodium methoxide or potassium methoxide solutions

\begin{tabular}{llll}
\hline & & \multicolumn{2}{l}{$\begin{array}{l}\text { Relative } \\
\text { concentrations }\end{array}$} \\
\cline { 4 - 5 } & Absorbance $(528 \mathrm{~nm})$ & 1 & 2 \\
\hline$[\mathrm{NaOMe}] / \mathrm{mol} \mathrm{dm}^{-3}$ & & & \\
1.0 & 0.678 & 1.0 & 0 \\
2.0 & 0.574 & 0.85 & 0.15 \\
2.4 & 0.355 & 0.52 & 0.48 \\
2.6 & 0.222 & 0.33 & 0.67 \\
2.8 & 0.208 & 0.30 & 0.70 \\
3.0 & 0.102 & 0.15 & 0.85 \\
3.2 & 0.088 & 0.13 & 0.87 \\
& & & \\
{$[\mathrm{KOMe}] / \mathrm{mol} \mathrm{dm}^{-3}$} & & & \\
1.5 & 0.675 & 1.0 & 0 \\
1.8 & 0.662 & 0.98 & 0.02 \\
2.0 & 0.653 & 0.97 & 0.03 \\
2.5 & 0.607 & 0.90 & 0.10 \\
3.0 & 0.472 & 0.70 & 0.30 \\
3.5 & 0.257 & 0.38 & 0.62 \\
4.0 & 0.105 & 0.16 & 0.84 \\
\hline
\end{tabular}

${ }^{a}$ Concentration is $3.6 \times 10^{-5} \mathrm{~mol} \mathrm{dm}^{-3}$.

use of the isosbestic point, eqn. (6) uses the condition of material balance, and eqn. (7) uses the known ${ }^{8}$ extinction coefficients of the adducts at $410 \mathrm{~nm}$. Once the relative concentrations were known the values of the indicator ratios, [2]/[1] and [3]/[2] could be calculated. Values obtained for potassium methoxide solutions are compared in Fig. 1 with corresponding values obtained from literature data with sodium methoxide. ${ }^{8}$

4-Cyano-2,6-dinitroanisole.-The adduct $1\left(\mathrm{X}=\mathrm{NO}_{2}, \mathrm{Y}=\right.$ $\mathrm{CN})$ has absorption maxima ${ }^{11}$ at $350 \mathrm{~nm}\left(\varepsilon 0.95 \times 10^{4} \mathrm{dm}^{3}\right.$ $\left.\mathrm{mol}^{-1} \mathrm{~cm}^{-1}\right)$ and $528 \mathrm{~nm}\left(\varepsilon 1.9 \times 10^{4}\right)$, and the $1: 2$ adduct 2 $\left(\mathrm{X}=\mathrm{NO}_{2}, \mathrm{Y}=\mathrm{CN}\right)$ was found to absorb at $368 \mathrm{~nm}$ but to have zero absorbance at $528 \mathrm{~nm}$. There was no evidence, at the base concentrations used, for formation of a $1: 3$ adduct. Thus measurements of absorbance at $528 \mathrm{~nm}$ given in Table 2 allowed the calculation of the relative concentrations of adducts. For both this compound and for 2-cyano-4,6-dinitroanisole slow fading reactions were observed, attributed ${ }^{11}$ to competitive methoxide attack at the cyano group, and absorbances were extrapolated to zero time.

2-Cyano-4,6-dinitroanisole.-The adduct 1 ( $\mathrm{X}=\mathrm{CN}, \mathrm{Y}=$ $\mathrm{NO}_{2}$ ) had absorption maxima ${ }^{11}$ at 374,382 and $466 \mathrm{~nm}(\varepsilon$ $1.8 \times 10^{4} \mathrm{dm}^{3} \mathrm{~mol}^{-1} \mathrm{~cm}^{-1}$ ), and the $1: 2$ adduct was found to absorb at $368 \mathrm{~nm}$. Absorbances of $466 \mathrm{~nm}$, given in Table 3, were used to calculate the relative concentrations of the adducts. Values of $\log _{10}[2] /[1]$ for this compound and its isomer are plotted in Fig. 2.

1-(2-Hydroxyethoxy)-2,4,6-trinitrobenzene.-Cyclisation of the parent compound occurs in very dilute base solutions ${ }^{13}$ to give the spiro-adduct 4 with $\lambda_{\max } 415$ and $474 \mathrm{~nm}$. In concentrated base solutions methoxide attack occurs at the 3 -

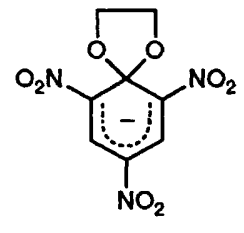


Table 3 Absorbances for solutions of 2-cyano-4,6-dinitroanisole ${ }^{a}$ in sodium methoxide or potassium methoxide solutions

\begin{tabular}{|c|c|c|c|}
\hline \multirow[b]{2}{*}[\mathrm{NaOMe}]{$/ \mathrm{mol} \mathrm{dm}^{-3}$} & \multirow[b]{2}{*}{ Absorbance $(466 \mathrm{~nm})$} & \multicolumn{2}{|c|}{$\begin{array}{l}\text { Relative } \\
\text { concentrations }\end{array}$} \\
\hline & & 1 & 2 \\
\hline $\begin{array}{l}1.5 \\
2.0 \\
2.3 \\
2.6 \\
3.0 \\
3.3 \\
3.5 \\
3.7 \\
4.0\end{array}$ & $\begin{array}{l}0.450 \\
0.450 \\
0.428 \\
0.388 \\
0.296 \\
0.184 \\
0.105 \\
0.071 \\
0.028\end{array}$ & $\begin{array}{l}1.0 \\
1.0 \\
0.95 \\
0.86 \\
0.66 \\
0.41 \\
0.23 \\
0.16 \\
0.06\end{array}$ & $\begin{array}{l}0 \\
0 \\
0.05 \\
0.14 \\
0.34 \\
0.59 \\
0.77 \\
0.84 \\
0.94\end{array}$ \\
\hline 4.0 & & \multicolumn{2}{|c|}{$\begin{array}{l}\text { Relative } \\
\text { concentrations }\end{array}$} \\
\hline$[\mathrm{KOMe}] / \mathrm{mol} \mathrm{dm}^{-3}$ & Absorbance $(470 \mathrm{~nm})$ & 1 & 2 \\
\hline 2.0 & 0.450 & 1.0 & 0 \\
\hline 2.4 & 0.450 & 1.0 & 0 \\
\hline 2.8 & 0.441 & 0.98 & 0.02 \\
\hline 3.0 & 0.438 & 0.97 & 0.03 \\
\hline 3.2 & 0.408 & 0.91 & 0.09 \\
\hline 3.4 & 0.374 & 0.83 & 0.17 \\
\hline 3.6 & 0.318 & 0.71 & 0.29 \\
\hline 4.0 & 0.194 & 0.43 & 0.57 \\
\hline 4.2 & 0.137 & 0.30 & 0.70 \\
\hline
\end{tabular}

${ }^{a}$ Concentration is $2.50 \times 10^{-5} \mathrm{~mol} \mathrm{dm}^{-3}$.

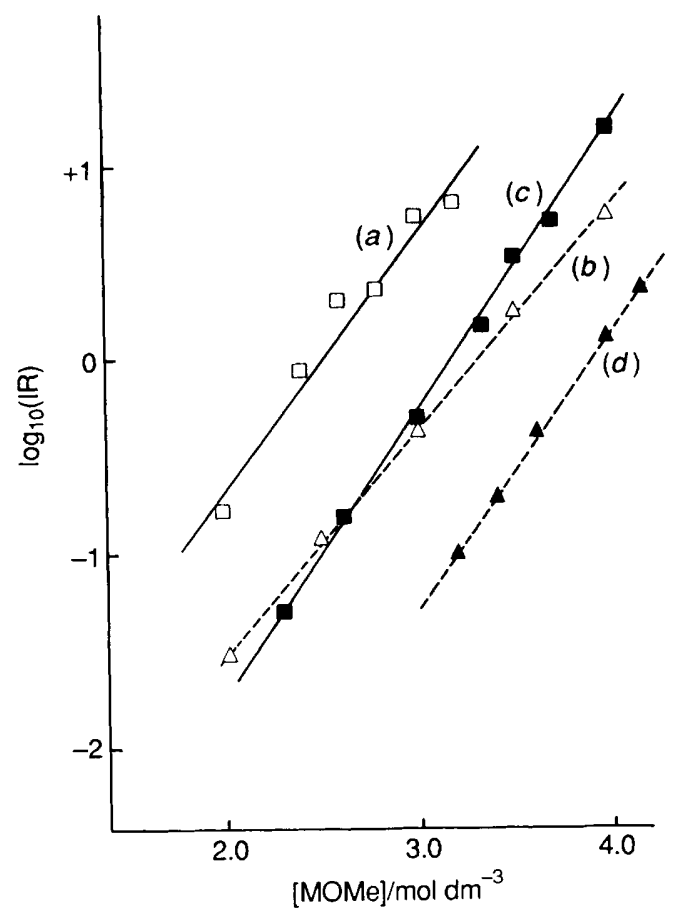

Fig. $2 \log _{10}\{[2] /[1]\}$ vs. [MOMe] for 4-cyano-2,6-dinitroanisole with sodium methoxide $(a)$ and potassium methoxide $(b)$, and for 2 cyano-4,6-dinitroanisole with sodium methoxide $(c)$ and potassium methoxide $(d)$

position to give a di-anion with $\lambda_{\max } 480 \mathrm{~nm}$, and at the 3- and 5positions to give a trianion which is transparent in the visible region. In solutions containing only the mono- and di-anionic species an isosbestic point was observed at $445 \mathrm{~nm}$. Measurements of absorption at this wavelength and at $415 \mathrm{~nm}$ allowed the relative concentrations of the three adducts present to be determined in a manner similar to that already described for

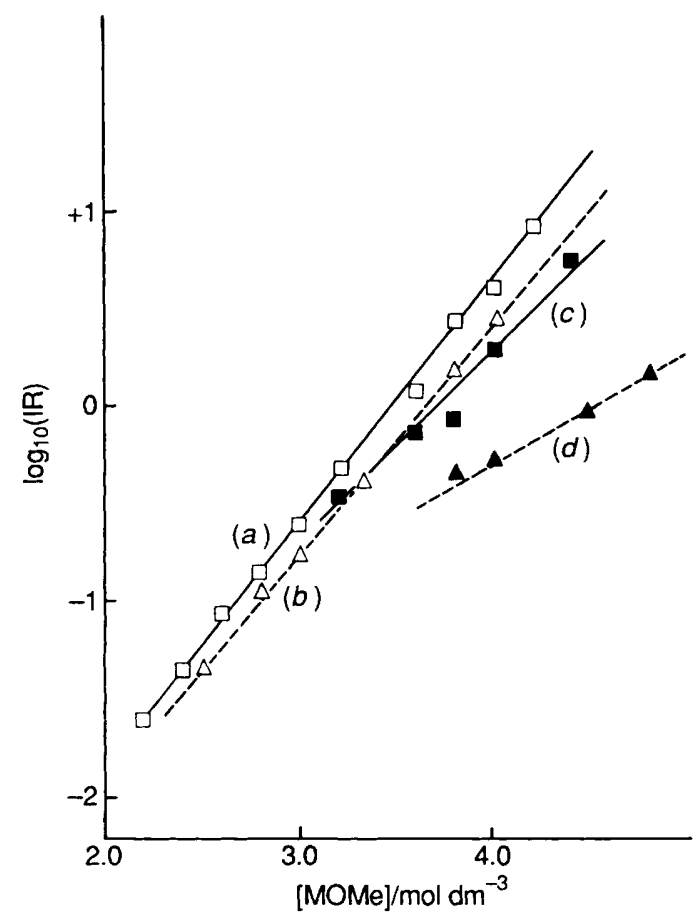

Fig. 3 Methoxide addition to the spiro adduct 4. $\log _{10}\{[2] /[1]\}$ $v s$. [MOMe] for reaction with sodium methoxide $(a)$ and potassium methoxide $(b) . \log _{10}\{[3] /[2]\}$ for sodium methoxide $(c)$ and potassium methoxide $(d)$.

2,4,6-trinitroanisole. Plots of the indicator ratios for sodium and potassium methoxides are in Fig. 3.

\section{Discussion}

The equilibria we have studied may, formally, be used to define the acidity functions given in eqns. (8) and (9). Here $J_{2 \mathrm{M}}^{2}$

$$
\begin{aligned}
& J_{2 \overline{\mathrm{M}}}^{2-}=\mathrm{p} K_{1,2}+\mathrm{p} K_{\mathrm{MeOH}}+\log _{10} \frac{[2]}{[1]} \\
& J_{3 \mathrm{M}}^{3-}=\mathrm{p} K_{2,3}+\mathrm{p} K_{\mathrm{MeOH}}+\log _{10} \frac{[3]}{[2]}
\end{aligned}
$$

indicates addition at two ring-positions to give a dianionic adduct and $J_{3 \mathrm{M}}^{3-}$ the corresponding addition at three ringpositions. $K_{1,2}$ and $K_{2,3}$ are, respectively, the thermodynamic equilibrium constants, referred to methanol as standard state, for conversion of 1 to 2 , and of 2 to 3 . In order to anchor the scales it is necessary to be able to either measure one or more equilibrium constant in dilute (ideal) solutions or to extrapolate data obtained from more concentrated solutions. The problem is that values of the indicator ratios [2]/[1] and [3]/[2] can only be made in concentrated base solutions and there is no accurate way to extrapolate to zero base concentration. For example, since $K_{1,2}$ must have a unique value independent of the cation, the essentially parallel lines $(a)$ and $(b)$ in Fig. 1 must be extrapolated to intercept the $y$ axis at zero base concentration with the same intercept. The problem of extrapolation has been noted previously ${ }^{12,18}$ in studies of the formation of $1: 1$ adducts from neutral parent molecules and has been shown ${ }^{9,12}$ to result from complexing of the $1: 1$ adducts with cations.

Nevertheless, since $K_{1,2}$ and $K_{2,3}$ are thermodynamic quantities they will have values which are independent of the cation, so that it is possible using eqns. (8) and (9) to compare the $J_{2 \mathrm{M}}^{2-}$ and $J_{3 \mathrm{M}}^{3-}$ basicities for sodium methoxide and potassium methoxide. 
Table 4 Relative 'basicities' of sodium methoxide and potassium methoxide solutions, given as $\Delta J_{2 \mathrm{M}}^{2-}(\mathrm{NaOMe}-\mathrm{KOMe})^{a}$

\begin{tabular}{|c|c|c|c|c|c|c|}
\hline \multirow[b]{2}{*}{ Indicator } & \multicolumn{6}{|c|}{ Base concentration $/ \mathrm{mol} \mathrm{dm}$} \\
\hline & 2.0 & 2.5 & 3.0 & 3.5 & 4.0 & 4.5 \\
\hline 2,4,6-Trinitroanisole & 1.08 & 1.13 & 1.17 & $\begin{array}{c}1.23 \\
(0.70)\end{array}$ & $\overline{(0.80)}$ & - \\
\hline 4-Cyano-2,6-dinitroanisole & 0.86 & 0.93 & 1.00 & - & - & - \\
\hline 2-Cyano-4,6-dinitroanisole & - & - & 1.02 & 1.06 & 1.08 & - \\
\hline Spiro-adduct, 4 & - & 0.14 & 0.18 & 0.22 & $\begin{array}{c}0.26 \\
(0.58)\end{array}$ & $\overline{(0.80)}$ \\
\hline $\begin{array}{c}\text { Aromatic Amines, }{ }^{b} \Delta H_{\mathrm{M}} \\
(\mathrm{NaOMe}-\mathrm{KOM})\end{array}$ & -0.49 & -0.62 & -0.69 & -0.78 & -0.87 & -0.98 \\
\hline
\end{tabular}

${ }^{a}$ Values in parentheses are $\Delta J_{3 \mathrm{M}}^{3-}(\mathrm{NaOMe}-\mathrm{KOMe}){ }^{b} H_{\mathrm{M}}$ values from reference 1.

This requires only a knowledge of the experimentally observable indicator ratios. Values of $\Delta J_{2 \mathrm{M}}^{2-}$, defined in eqn. (10), and

$$
\Delta J_{2 \mathrm{M}}^{2-}=J_{2 \mathrm{M}}^{2-}(\mathrm{NaOMe})-J_{2 \mathrm{M}}^{2-}(\mathrm{KOMe})
$$

corresponding values of $\Delta J_{3 \mathrm{M}}^{2}$ calculated at different base concentrations are given in Table 4 . Interestingly the values for all indicators are positive showing that for these equilibria sodium methoxide solutions are more 'basic' than the corresponding potassium methoxide solutions. Also, at a given base concentration, the value of $\Delta J_{2 \mathrm{M}}^{2-}$ depends on the indicator used showing that no unique $J_{2 \mathrm{M}}^{2-}$ scales exist which are independent of the indicator. The values of $\Delta H_{\mathrm{M}}$, also given in Table 4 , show that for the aromatic amines used as indicators potassium methoxide solutions are more 'basic' than corresponding sodium methoxide solutions. This latter observation has been attributed to the stronger ion-pairing of methoxide with sodium ions than with potassium ions, ${ }^{4.6}$ and this factor will not vary with the nature of the indicator. What, then, is the reason for the basicity inversion observed here with the $J_{2 \mathrm{M}}^{2-}$ indicators?

Two possible explanations are: (i) differences between the solvating abilities of sodium and potassium methoxide solutions, or (ii) specific interactions with cations of anionic forms of the indicators. It has been widely recognised that the different solvational requirements of different indicator types may lead to important differences in acidity function behaviour; ${ }^{1-5,19}$ this aspect was emphasised in a recent report. ${ }^{7}$ However, the basicity inversion between the $H_{\mathrm{M}}$ and $J_{2 \mathrm{M}}^{2-}$ scales requires a difference in solvating power between sodium methoxide and potassium methoxide solutions of the same concentration. To develop this argument, proton loss from the aromatic amines used to define the $H_{\mathrm{M}}$ function will produce delocalised anions in which solvation by methanol is likely to be less important than in the adducts 2 and 3 used to define $J_{2 \mathrm{M}}^{2-}$ and $J_{3 \mathrm{M}}^{2-}$ functions. The latter two adducts carry localised negative charges which may be strongly solvated by methanol by hydrogen-bonding interactions. Thus the attribution of the observed basicity inversion to solvation differences requires that methanolic sodium methoxide is a better solvating medium than methanolic potassium methoxide. Bagno et al. ${ }^{7}$ have argued oppositely that methanol in sodium methoxide solutions should be less available for solvation because the solvent is more involved in solvating the smaller sodium cation. The case may be overstated since the stronger ion-pairing of sodium methoxide than of potassium methoxide will reduce the concentration of free sodium ions. In fact, the measured activities of methanol in solutions of sodium and potassium methoxide are almost identical up to $4 \mathrm{~mol} \mathrm{dm}^{-3}$ concentration. ${ }^{20}$ We thus think that it is unlikely that solvation is the major factor responsible for the positive values of $\Delta J_{2 \mathrm{M}}^{2}$. The strong interactions of the $1: 1$ adducts 1 with cations are well-documented ${ }^{9-12}$ so that it seems reasonable that the higher adducts 2 and 3 will also interact. We thus prefer the second explanation, that the higher adducts show strong specific interactions with cations and that their stronger interaction with sodium than with potassium ions results in the enhanced $J_{2 \mathrm{M}}^{2-}$ values for sodium methoxide solutions.

Relative Strengths of Association with $\mathrm{Na}^{+}$and $\mathrm{K}^{+}$.- We include the association of adducts with cations (Scheme 1). Here

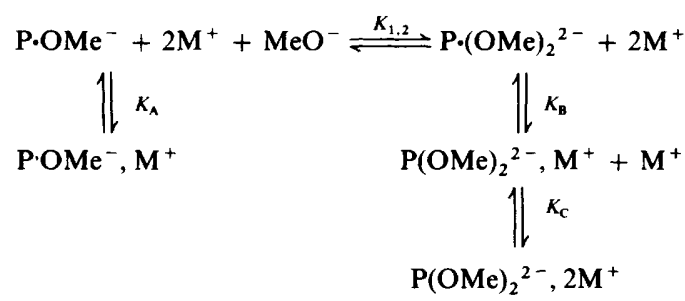

Scheme 1

$K_{\mathrm{A}}$ is the association constant of the $1: 1$ adduct with cations, and $K_{\mathrm{B}}$ and $K_{\mathrm{C}}$ measure the interaction of the $1: 2$ adduct with one and two cations, respectively. The values of thermodynamic equilibrium constants, $K_{1,2}$, are not determinable, but we may define an apparent equilibrium constant, $K_{\text {app }}$, in terms of the known indicator ratios and the basicity of the medium. We require here a measure of the basicity which includes all deviations from ideality apart from the specific association of adducts with cations. There is no completely satisfactory way to do this. However, there is good evidence ${ }^{4,7,9}$ that the aromatic amine indicators used to define the $H_{\mathrm{M}}$ scale do not strongly associate with cations. Hence we use $h_{\mathrm{m}}$, defined in eqn. (11), in the determination of $K_{\mathrm{app}}$ as shown in eqn. (12). Since $h_{\mathrm{M}}$ values

$$
\begin{gathered}
\log _{10} h_{\mathrm{m}}=H_{\mathrm{M}}-\mathrm{p} K_{\mathrm{MeOH}} \\
K_{\mathrm{app}}=\frac{[2]}{[1] \cdot h_{\mathrm{M}}}
\end{gathered}
$$

include basicity effects resulting from association of metal cations with methoxide ions, this association has not been shown in Scheme 1. $K_{\text {app }}$ may now be related in eqn. (13) to individual equilibrium constants. If, as we expect, ${ }^{9}$ the values of the association constants $K_{\mathrm{A}}$ and $K_{\mathrm{B}}$ are $>10$ then eqn. (13) simplifies to eqn. (14). Combination of these equations with eqn. (8) leads to eqn. (15). Absolute values of $J_{2 \mathrm{M}}^{2-}$ are not

$$
\begin{gathered}
K_{\text {app }}=\frac{K_{1,2}\left(1+K_{\mathrm{B}}\left[\mathrm{M}^{+}\right]\right)\left(1+K_{\mathrm{c}}\left[\mathrm{M}^{+}\right]\right)}{1+K_{\mathrm{A}}\left[\mathrm{M}^{+}\right]} \\
K_{\mathrm{app}}=\frac{K_{1,2} K_{\mathrm{B}}\left(1+K_{\mathrm{c}}\left[\mathrm{M}^{+}\right]\right)}{K_{\mathrm{A}}} \\
\log _{10}\left\{\frac{K_{\mathrm{B}}}{K_{\mathrm{A}}}\left(1+K_{\mathrm{c}}\left[\mathrm{M}^{+}\right]\right)\right\}=J_{2 \mathrm{M}}^{2-}-H_{\mathrm{M}}
\end{gathered}
$$


Table 5 Estimate of the relative strengths of association of $\mathbf{2}$ and $\mathbf{3}$ with sodium and potassium ions

\begin{tabular}{|c|c|c|c|c|c|c|}
\hline \multirow[b]{2}{*}{ Indicator } & \multicolumn{6}{|c|}{ Base concentration $/ \mathrm{mol} \mathrm{dm}^{-3}$} \\
\hline & 2.0 & 2.5 & 3.0 & 3.5 & 4.0 & 4.5 \\
\hline \multicolumn{7}{|l|}{$\Delta J_{2 \mathrm{M}}^{2}-\Delta H_{\mathrm{M}}$} \\
\hline 2,4,6-Trinitroanisole & 1.57 & 1.75 & 1.86 & 2.01 & - & - \\
\hline 4-Cyano-2,6-dinitroanisole & 1.35 & 1.55 & 1.69 & - & - & - \\
\hline 2-Cyano-4,6-dinitroanisole & - & - & 1.71 & 1.84 & 1.95 & - \\
\hline Spiro-adduct, 4 & - & 0.76 & 0.87 & 1.00 & 1.13 & - \\
\hline \multicolumn{7}{|l|}{$\Delta J_{3 \mathrm{M}}^{2-}-\Delta H_{\mathrm{M}}$} \\
\hline 2,4,6-Trinitroanisole & - & - & - & 1.48 & 1.67 & - \\
\hline Spiro-adduct, 4 & - & - & - & - & 1.45 & 1.78 \\
\hline
\end{tabular}

known but using eqn. (10) values of $\Delta J_{2 \mathrm{M}}^{2-}$, reflecting the difference in basicities of sodium methoxide and potassium methoxide solutions, have been calculated and are given in Table 4. Ratios of association constants for $\mathrm{Na}^{+}$and $\mathrm{K}^{+}$can therefore be compared, eqn. (16). Further, it is known ${ }^{9,11}$ that $1: 1$ adducts associate with aproximately equal strengths with sodium and potassium ions, so that the values of $K_{\mathrm{A}}^{\mathrm{Na}^{+}}$and $K_{\mathrm{A}}^{\mathrm{K}^{+}}$will be similar. Hence eqn. (16) can be simplified to give eqn. (17).

$$
\begin{aligned}
& \log _{10} \frac{\left\{\frac{K_{\mathrm{B}}^{\mathrm{Na}^{+}}}{K_{\mathrm{A}}^{\mathrm{Na}^{+}}}\left(1+K_{\mathrm{c}}^{\mathrm{Na}+}\left[\mathrm{Na}^{+}\right]\right)\right\}}{\left\{\frac{K_{\mathrm{B}}^{\mathrm{K}^{+}}}{K_{\mathrm{A}}^{\mathrm{K}^{+}}}\left(1+K_{\mathrm{c}}^{\mathrm{K}^{+}}\left[\mathrm{K}^{+}\right]\right)\right\}}=J_{2 \mathrm{M}}^{2-}-\Delta H_{\mathrm{M}} \\
& \log _{10}\left\{\frac{K_{\mathrm{B}}^{\mathrm{Na}^{+}}\left(1+K_{\mathrm{c}}^{\mathrm{Na}^{+}}\left[\mathrm{Na}^{+}\right]\right)}{K_{\mathrm{B}}^{\mathrm{K}^{+}}\left(1+K_{\mathrm{c}}^{\mathrm{K}^{+}}\left[\mathrm{K}^{+}\right]\right)}\right\}=\Delta J_{2 \mathrm{M}}^{2-}-\Delta H_{\mathrm{M}}
\end{aligned}
$$

Values of the right-hand side of eqn. (17) are given in Table 5. Because of the assumptions made they should be regarded as giving orders of magnitude rather than precise values. However, they do reflect the very much stronger association of $1: 2$ adducts with sodium ions than with potassium ions. The increases in value with increasing base concentration (metal ion concentration) may reflect the higher values of $K_{\mathrm{c}}$ for sodium than for potassium ions. In a similar fashion the positive values of $\left(\Delta J_{3 \mathrm{M}}^{3-}-\Delta H_{\mathrm{M}}\right)$ show the stronger association of $1: 3$ adducts 3 with sodium ions than with potassium ions.

It has been shown previously ${ }^{9-11}$ that association of the $1: 1$ adducts 1 with cations involves the oxygen atoms of the methoxy groups and of the ortho-ring substituents as shown in 5 , the presence of the dioxolane ring in 4 precluding such association. ${ }^{21}$ For the $1: 1$ adducts equilibrium constants for association with sodium and with potassium ions have similar values. In the $1: 2$ adduct 2 and its spiro-analogue, and in the $1: 3$ adducts, 3 , negative charge is localised on nitro groups. The<smiles>[Y]c1cc([Y](=O)[O-])cc([N+](=O)[O-])c1</smiles>

$\mathbf{5}$<smiles>[Y]C1=CC([Y])C(OC)(OC)C(=O)C1(OC)O[Na]</smiles>

6

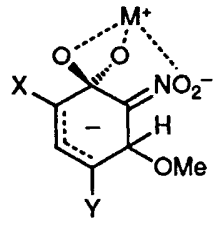

7 larger association constants of these adducts with sodium than with potassium ions may be rationalised by the stronger association of the smaller cation with the localised negative charge as shown in 6. Nevertheless the data in Table 5 show a distinction between the relative complexing abilities of $1: 2$ adducts formed from anisoles and from the spiro-adduct 4 . It may be that the gem-dimethoxy function still has an active part to play in cation complexing so that interactions such as that shown in 7 are particularly favourable for sodium ions.

\section{References}

1 C. H. Rochester, Acidity Functions, Academic Press, London, 1970.

2 C. H. Rochester, Quart. Rev. (London), 1966, 20, 511.

3 K. Bowden, Chem. Rev., 1966, 66, 119.

4 F. Terrier, Ann. Chim. (Paris), 1969, 4, 153.

5 F. Terrier, F. Millot and R. Schaal, Bull. Soc. Chim. Fr., 1969, 3002.

6 J. R. Jones, J. Chem. Soc., Chem. Commun., 1968, 513.

7 A. Bagno, G. Scorrano and F. Terrier, J. Chem. Soc., Perkin Trans. 2 , $1990,1017$.

8 C. H. Rochester, J. Chem. Soc., 1965, 2404.

9 M. R. Crampton and H. A. Khan, J. Chem. Soc., Perkin Trans. 2, (a) 1972, 1173; (b) 1972, 2286; (c) 1973, 1103; (d)M. R. Crampton, $J$. Chem. Soc., Perkin Trans. 2, 1975, 825.

10 S. Sekiguchi, T. Aizawa and M. Aoki, J. Org. Chem., 1981, 46, 3657.

11 P. C. M. F. Castilho, M. R. Crampton and J. Yarwood, J. Chem. Res., 1989, (S), 370; $(M), 2801$.

12 V. Gold and J. Toullec, J. Chem. Soc., Perkin Trans. 2, 1979, 596.

13 E. Buncel, M. R. Crampton, M. J. Strauss and F. Terrier, Electron Deficient Aromatic and Heteroaromatic Base Interactions, Elsevier, Amsterdam, 1984.

14 O. L. Brady and H. V. Horton, J. Chem. Soc., 1925, 2230.

15 J. E. Dickeson, L. K. Dyall and V. A. Pickles, Aust. J. Chem., 1968, 21, 1267.

16 J. J. Blanksma, Recl. Trav. Chim. Pays-Bas, 1901, 20, 411.

17 M. R. Crampton and M. J. Willison, J. Chem. Soc., Perkin Trans. 2, $1974,1681,1686$.

18 C. F. Bernasconi, J. Am. Chem. Soc., 1968, 90, 4982.

19 M. R. Crampton, J. Chem. Soc., Perkin Trans. 2, 1975, 185.

20 F. Terrier, Compt. Rend. Acad. Sci., Ser. C, 1967, 265, 1433.

21 M. R. Crampton, J. Chem. Soc., Perkin Trans. 2, 1973, 2157. 